\title{
Vulnerabilidad entre derechos humanos y bioética. Relaciones tormentosas, conflictos insolutos
}

\section{Vulnerability, human rights, and bioethics. Turbulent relationships, unsolved conflicts}

\section{MIGUEL KOTTOW*}

Resumen: La confusión entre vulnerabilidad (daño potencial) y vulneración (daño instalado) ha tenido consecuencias importantes, sobre todo al afirmarse que la vulnerabilidad conlleva la incapacidad de velar por los propios intereses. La vulnerabilidad es un rasgo antropológico que implica la libertad y la igualdad de todos los individuos, como es proclamado por los derechos humanos, y reconocido por la ética trascendental que inspira todo quehacer humano. La universalidad de los derechos básicos ha sido cuestionada porque solo son reclamables por personas con ciudadanía reconocida, y porque hay grupos sociales y culturas que prefieren marcar su singularidad y especificar los derechos.

Los derechos primarios de libertad requieren ser complementados con derechos políticos y sociales que atienden a las necesidades de individuos vulnerados, cuidando de aliviar sus desmedros y falta de empoderamiento. Este lenguaje es asumido por la bioética, entendida como la ética aplicada que reflexiona sobre intervenciones humanas en procesos vitales. Con el propósito de proteger a los vulnerados, la bioética delibera sobre decisiones sensibles involucradas en estas intervenciones, y sobre políticas públicas que norman prácticas sociales pertinentes a su ámbito de reflexión.

Palabras clave: bioética - derechos humanos - vulnerabilidad

Summary: Vulnerability as potential harm has been confused with actual damage, leading to the improper conclusion that those already harmed, therefore wrongly called vulnerable, are considered unable to take care of their own interests. Fragile, but as yet unharmed, vulnerability is an anthropological trait that implies liberty and equality as proclaimed by human rights, as well as by the ethics fundamental to all human endeavors. The universality of human rights has been put to question, arguing that they can only be claimed by individuals who are recognized as citizens. Also, different cultures and specific social groups demand the recognition of rights that are respectful of their singularity, and therefore not universal.

The fundamental rights to liberty need to be complemented by political and social rights that take care of actual needs, harms and disempowerment. This kind of language is proper to bioethics, a discipline focused upon human interventions on vital processes, deliberating upon sensitive issues that

Médico, profesor titular de la Universidad de Chile, académico de la Escuela de Salud Pública, de la Facultad de Medicina de Santiago de Chile. Correo electrónico: mkottow@gmail.com 
require decisions as well as normative public policies of social practices that pertain to its realm of reflection.

Keywords: bioethics - human rights - vulnerability

CONTENIDO: I. INTRODUCCIÓN.- II. VULNERABILIDAD.- II.1. COMO RASGO ANTROPOLÓGICO.- II.2. EL SER HUMANO VULNERADO.- II.3. VULNERABILIDAD MORAL.- III. DERECHOS HUMANOS.- III.1. DERECHO NATURAL.III.2. DERECHOS CIUDADANOS.- III.3. CRÍTICAS CULTURALES.- IV. BIOÉTICA Y DERECHOS HUMANOS.- V. BIOÉTICA Y VULNERABILIDAD.- VI. BIOÉTICA COMO ÉTICA APLICADA.- VII. CONCLUSIÓN (¿?).

\section{INTRODUCCIÓN}

Los términos del título han sido ampliamente debatidos desde muy diversas perspectivas, terminandopor crear confusiones y contradicciones que han enturbiado notablemente el discurso, dando paso a conclusiones controvertidas que lesionan, en vez de esclarecer la deliberación bioética. Si se entiende la bioética como una ética enfocada, en lo fundamental, a reflexionar sobre la intervención humana en procesos vitales, queda a la vista que las polémicas teóricas interminables tensionan la paciencia de quienes requieren orientación tanto en decisiones prácticas, como en la formulación de normas y políticas públicas sobre asuntos que interesan y preocupan a la ciudadanía. Las aplicaciones tecnocientíficas sobre los extremos de la vida, la manipulación genética, los debates acerca de derechos y equidad en salud, la biotecnología de avanzada y tantos otros asuntos no han llegado a puerto, puesto que continúan las indecisiones en la práctica clínica y en la investigación médica, las disquisiciones conflictuales sobre el comienzo de la vida humana y el proceso de muerte. Las políticas públicas normativas en materias que competen a la bioética no logran acallar las controversias ante la imposibilidad de llegar sea a compromisos aceptables, o a la convivencia tolerante de diversas posturas. Anémicos han sido los mecanismos para asegurar la participación ciudadana en asuntos que a todos interesan, perpetuándose la lógica deductiva que deriva regulaciones legales y normas de conducta a partir de un puñado de máximas que se arrogan indebidamente validez universal.

Es preciso depurar los conceptos y revisar las dependencias entre ellos, porque las confusiones semánticas y conceptuales no hacen sino incrementar los desniveles de conocimiento y poder, dando aparente legitimidad al discurso ad verecundiam y a las prácticas autoritarias, reforzando el proceso que Habermas llamara la colonización de la razón comunicativa por la razón instrumental. El presente trabajo se propone colaborar en los intentos de esclarecimiento de estos grandes temas, abocándose a la tarea con una mirada pragmática que rechaza 
las pretensiones de verdad, la justificación esencialista, las hegemonías doctrinarias, los argumentos incorregibles.

\section{VULNERABILIDAD}

VULNERABILIDAD ENTRE DERECHOS

HUMANOS

Y BIOÉTICA.

RELACIONES

TORMENTOSAS,

CONFLICTOS

INSOLUTOS

VULNERABILITY,

HUMAN RIGHTS,

AND BIOETHICS.

TURBULENT

RELATIONSHIPS,

UNSOLVED

CONFLICTS dejando a la vista cuán vasallo es de la ayuda humana y de la compasión colectivas $»^{2}$. También para Pascal es lo vivo radicalmente vulnerable: «Entre nosotros y el infierno o el cielo no existe más que la vida, que es la cosa más frágil del mundo» ${ }^{3}$. Fragilidad que es extrema en el ser humano: «El hombre no es más que una caña, la más frágil de la naturaleza, pero es una caña pensante. No hace falta que el universo entero se arme para destruirlo, un vapor, una gota de agua es suficiente para matarlo» ${ }^{4}$.

Las vulnerabilidades humanas no son únicamente características y persistentes (vale decir vulnerabilidades de la especie), sino variables y selectivas. Los seres humanos son, por de pronto, persistentemente vulnerables en modos que son típicos para toda la especie: tienen una infancia prolongada e indefensa; las más esenciales capacidades físicas y sociales solo se adquieren con el apoyo de otros; dependen de prolongadas interacciones sociales y emocionales con otros; sus vidas dependen de hacer uso estable y productivo tanto del mundo natural como del creado por el hombre (son estas algunas de las razones por que son míticos los seres humanos radicalmente

1 PAscal, Blais. Pensamientos. Madrid: Alianza Editorial, 1986, fragmento 152. Los «Pensées» de Pascal se presentan como fragmentos que han sido diversamente ordenados. La numeración aquí presentada es de Louis Lafuma, traductor y considerado el más acucioso recopilador de la obra de Pascal.

2 Ibídem, fragmento 200.

3 O'NeILL, Onora. Towards Justice and Virtue. A Constructive Account of Practical Reasoning. Cambridge/Nueva York: Cambridge University Press, 1998, pp. 191-192.

4 RendtorfF, Jacob Dahl \& Peter Kemp. Basic Ethical Principles in European Bioethics and Biolaw (volúmenes 1-2). Copenhague/Barcelona: Centre for Ethics and Law, Copenhagen/Institut Borja de Bioética, Barcelona, 2000, p. 46. 
solitarios pero competentes). La protección contra injurias en vista de estas vulnerabilidades ubicuas y predecibles de la condición humana, son en gran medida tarea de la justicia ${ }^{5}$.

El Proyecto BIOMED-II también definió la vulnerabilidad como inherente a la condición humana:

La descripción de vulnerabilidad es considerada como una descripción de integridad personal. El ser humano corpóreamente encarnado es visto como vulnerable en el sentido de poder ser dañado, sometido a riesgos y amenazas contra su integridad [...] Ciertamente, la característica de temporalidad y finitud de la vida humana indica que la condición humana es muy frágil. La vulnerabilidad significa que debemos vivir con la mortalidad ${ }^{6}$.

Es de notar que estas definiciones entienden que el vulnerable no está dañado, pues aún cuenta con su integridad personal que se encuentra amenazada, o sea, potencialmente dañable, pero no de hecho dañada. La vulnerabilidad de la vida está marcada por su eventual e inevitable extinción, lo que da pábulo a entenderla como la fragilidad última del proyecto existencial, un Dasein permanentemente en riesgo de fracasar, pero aún no fracasado.

Para remarcar aún más la distinción entre vulnerabilidad persistente y vulnerabilidad selectiva, se ha propuesto hablar de vulnerabilidad como rasgo existencial y de susceptibilidad en personas o grupos humanos que han dejado de ser potencialmente dañables por cuanto ya han sufrido un desmedro que los amenaza con daños adicionales y para quienes, para diferenciar las dos categorías, se sugirió el terminado mulcados?.

Estas observaciones sobre vulnerabilidad han tenido dos giros que las impurifican y alejan del concepto prístino de vulnerabilidad como condición humana frágil. Por una parte, la vulnerabilidad es elevada a ser «el más esencial de los principios en bioética y bioderecho» ${ }^{8}$, lo que aparece como una flagrante violación de la falacia naturalista, puesto que una descripción antropológica es elevada, sin intermediación, a la categoría normativa del más primario de los principios bioéticos ${ }^{9}$. Por otra parte, la vulnerabilidad vinculada a la integridad es precipitadamente interpretada como vulneración

5 El término latino mulcatus quiere decir dañado. Koтtow, Miguel. Ética de protección. Bogotá: Universidad Nacional de Colombia, 2007.

6 Kotrow, Miguel. «Vulnerability: What Kind of Principle Is It?». Medicine, Health Care and Philosophy, VII, 3 (2004), pp. 281-287.

7 FAYOS FEBRER, Rafael. «Vulnerabilidad e indigencia de la condición humana». En CAYUELA, Aquilino (ed.). Vulnerables: Pensar la fragilidad humana. Madrid: Ediciones Encuentro, 2005, pp. 10-30, pp. 16-17.

8 KIPNIS, Kenneth. «Seven Vulnerabilities in the Pediatric Research Subject». Theoretical Medicine and Bioethics, 24, 2 (2003), pp. 107-120.

9 Ibídem, p 46. 
reparable: «La enfermedad es una alteración del estar-en-el-mundo y expresa nuestra fundamental vulnerabilidad. Así, la medicina es una compensación por la vulnerabilidad existencial del ser humano» ${ }^{10}$. La medicalización de la existencia humana es uno de los primeros efectos negativos, por haber permitido el deslizamiento de un concepto antropológico hacia una situación de daño corpóreo requirente de atención terapéutica a solicitud de un principio bioético.

Las administraciones de apoyo y cuidado también se han expresado en términos sociales:

Cuando decimos que el hombre es apertura al mundo, queremos manifestar la ausencia de clausura en razón de la falta de especialización biológica y de vinculación instintiva al medio que encontramos en los animales. Esto hace al hombre vulnerable y radicalmente dependiente de los demás. Vulnerable porque mientras no aprenda a relacionarse con el mundo, a dominarlo y a controlarlo, este será una amenaza para él ${ }^{11}$.

Dominar y controlar el mundo, ya lo dijo Francis Bacon, es la antesala desde donde mejorar el sino de la humanidad, pero resulta difícil imaginar cómo los fundamentos éticos y los mecanismos sociales conseguirán que los logros tecnocientíficos sean puestos a disposición de todo ser humano a fin de permitirle reducir individualmente su vulnerabilidad existencial.

Es preciso insistir que, en tanto se reconozca la vulnerabilidad como atributo antropológico esencial, habrá de evitarse entenderla como principio bioético u homologarla con desmedros ya instalados. El camino desde la descripción hacia una prescripción ética con pretensiones de universalidad es materia de una reflexión compleja y aún inédita.

\section{II.2. El ser humano vulnerado}

La mayoría de los aportes al discurso bioético sobre vulnerabilidad ha preferido el concepto minimalista, pero equivocado, de relacionar vulnerabilidad con daño establecido. Desde la bioética en investigación con seres humanos se ha reclamado el uso desmedido e impreciso, por el Informe Belmont y otros documentos regulatorios, del predicar vulnerabilidad en individuos y grupos sociales desaventajados; asimismo, también se pretende atribuir vulnerabilidad y negar autonomía de decisión informada a personas dependientes — prisioneros_-, o que tienen competencia mental limitada, pero de ningún modo abolida. Arbitrariamente se homologa «vulnerabilidad»

10 Council For International ORganizations of Medical SCIENCES. Pautas éticas internacionales para la investigación biomédica en seres humanos. Ginebra: CIOMS/OPS/OMS, 2002, p. 69.

11 RHODES, Rosamond. «Rethinking Research Ethics». American Journal of Bioethics, V, 1 (2005), pp. 7-28.

VULNERABILIDAD ENTRE DERECHOS

HUMANOS

Y BIOÉTICA.

RELACIONES

TORMENTOSAS,

CONFLICTOS

INSOLUTOS

VULNERABILITY,

HUMAN RIGHTS,

AND BIOETHICS.

TURBULENT

RELATIONSHIPS,

UNSOLVED

CONFLICTS 
con daño y con incapacidad para tomar decisiones ${ }^{12}$. De este modo se identifica subpoblaciones como vulnerables según el tipo de desmedro que de hecho sufren, llegando a tipificar vulnerabilidades como causas de supuesta incapacidad de personas para llegar a un consentimiento informado. Esta clasificación opera como una «taxonomía que ofrece distinciones útiles, que llevan a las dos inferencias que cualquier persona que calza con alguna de estas categorías es vulnerable, en tanto que todo individuo capaz de consentir sin interferencias no lo es» ${ }^{13}$.

Pero este, señalan los autores, es un uso excesivamente amplio y, a su vez, demasiado restringido del término vulnerabilidad. Muy amplio, porque la multitud de criterios de vulnerabilidad termina por englobar a todos hasta convertirla en «un concepto demasiado nebuloso para ser significativo», y demasiado estrecho por concentrarse en características grupales y desatender la posibilidad de daño físico individual ${ }^{14}$. El uso inflacionario de la categoría vulnerabilidad tiene consecuencias éticas considerables, si se sindica a las personas vulnerables como «absoluta o relativamente incapaces de proteger sus propios intereses. Específicamente, pueden tener insuficiente poder, inteligencia, educación, recursos, fuerza u otros atributos necesarios para proteger sus intereses» ${ }^{15}$. Tampoco es éticamente tranquilizador leer que «toda población o grupo al interior de una sociedad debe considerarse como vulnerable si carece de derechos fundamentales y libertades que forman una parte esencial para decidir el curso básico de su vida» ${ }^{16}$. Personas en las situaciones descritas no son potencialmente vulnerables, sino de hecho profunda y esencialmente carenciadas.

Hay en lo presentado una doble falacia: primero, por confundir vulnerable con vulnerado, ya que el sufijo ble «indica posibilidad pasiva, es decir, capacidad o aptitud para recibir el verbo» ${ }^{17}$. Y segundo, al deducir que todo vulnerable/vulnerado es imputado como incapaz de tomar decisiones autónomas, como si todo daño — corpóreo, psíquico o social - implicara sin más la pérdida de la competencia mental.

En una argumentación diametralmente opuesta a la de quienes postulan la vulnerabilidad como condición humana, se señala: «el peligro que entraña sostener la noción existencial y esencialista de la vulnerabilidad es el riesgo de naturalizar la vulnerabilidad e ignorar la vulnerabilidad que se da en la situación de investigación. Así, si todos somos igualmente

12 JOFFE, Steven \& Franklin Miller. «Bench to Bedside: Mapping the Moral Terrain of Clinical Research». The Hastings Center Report, 38, 2 (2008), p. 40.

13 HONNETH, Axel. «Recognition and Moral Obligation». Social Research, 64, 1 (1997), p. 28.

14 HonNETH, Axel. Crítica del agravio moral. Buenos Aires: Fondo de Cultura Económica de Argentina, 2009.

15 HONNETH, Axel. «Recognition and Moral Obligation», p. 20.

16 Ibídem, p. 23.

17 MARITAIN, Jacques. Natural Law. Reflections on Theory and Practice. South Bend: St. Augustine's Press, 2001, p. 58. 
vulnerables, nadie es específicamente vulnerable, es más, nadie necesita de ninguna protección especial ${ }^{18}$. Para evitar esta supuesta negligencia, la autora propone una «concepción estratificada por capas» para constituir la vulnerabilidad en una «sutil herramienta que permita identificar toda la exuberancia que presenta la realidad y exhiba todas las diferencias y variaciones que ella ofrece» ${ }^{19}$. No obstante, para hacer valer estas diferenciaciones, sería preferible reservar la vulnerabilidad como atributo antropológico general y reconocer como vulneradas o mulcadas a las personas que, habiendo perdido su integridad, ya no son frágiles y potencialmente dañables, sino de hecho y concretamente desmedradas.

Este último aporte al debate deja en claro que no estamos frente a una mera escaramuza semántica, por cuanto el modo de entender vulnerabilidad tiene importantes consecuencias para la bioética. La crítica de que la vulnerabilidad existencial y esencialista naturaliza el concepto, lleva precisamente a la conclusión opuesta de la presentada. Si la vulnerabilidad es estratificada, clasificada según el desmedro, o tipificada según la causa que impide un consentimiento informado adecuado, se termina en la postura de diagnosticar vulnerabilidades en forma genérica sin especificar el daño y asumir la reparación. Por ejemplo, si las personas con competencia mental reducida son entendidas como «vulnerables», no resulta comprensible que sean incorporadas impositivamente en estudios clínicos no terapéuticos, en vez de especificar su daño y respetar que no pueden ser reclutados como sujetos de una investigación carente de todo beneficio médico para ellos ${ }^{20}$.

Al no definir los desmedros que sufren los vulnerados, escondiendo las especificidades bajo la etiqueta «vulnerables», no habrá tampoco la instauración remedial y compensatoria de los daños presentes. Esta negligencia se observa en protocolos de investigación a realizarse en poblaciones pobres y escasamente educadas, que son catalogadas como vulnerables con el fin de anticipar eventuales dificultades en sonsacar el consentimiento informado, pero no para instaurar programas específicos de equidad social y educación. El caso más craso es reconocer a los pacientes como individuos «vulnerables» para luego reclutarlos como probandos (sujetos de investigación), que carecerán de protección médica y ético-clínica, arguyendo que: «la conclusión más razonable es que los RCT [Randomized Clinical Trials] deben regirse por normas éticas apropiadas para la investigación clínica, que difieren del beneficio

18 LUNA, Florencia. «Vulnerabilidad: un concepto muy útil. Abandonando los "corsets teóricos” . Revista Redbioética/UNESCO, 2, 1 (2011), pp. 85-90, p. 86.

VULNERABILIDAD ENTRE DERECHOS

HUMANOS

Y BIOÉTICA.

RELACIONES

TORMENTOSAS,

CONFLICTOS

INSOLUTOS

VULNERABILITY,

HUMAN RIGHTS,

AND BIOETHICS.

TURBULENT

RELATIONSHIPS,

UNSOLVED

CONFLICTS 
terapéutico y la no maleficencia terapéutica ${ }^{21}$. «La orientación científica ayuda a especificar adecuadamente los principios éticos biomédicos del contexto de la investigación clínica como distintos a los cuidados médicos ${ }^{22}$. Estas muy discutibles propuestas ignoran la distinción vulnerable/vulnerado y delatan su confusión al investigar en pacientes — vulnerados_, sin atender adecuadamente a su consentimiento informado, puesto que al catalogarlos de vulnerables también se les imputa incompetencia mental. Se explica así la tendencia a considerar como poblaciones vulnerables a aquellas que «están en riesgo de ser mal utilizadas en el curso de investigaciones biomédicas ${ }^{23}$.

\subsection{Vulnerabilidad moral}

Si Rousseau consideraba el estado natural del ser humano como vulnerable al punto de impedirle la sobrevivencia, pone Hobbes el acento en que no es la naturaleza, sino el agresivo congénere quien amenaza la vulnerabilidad por negarse a reconocer y respetar al prójimo como sujeto moral: «moralidad es la quintaesencia de actitudes que nos obligamos mutuamente a adoptar a fin de asegurar conjuntamente las condiciones de nuestra integridad personal $»^{24}$.

El ser humano solo sobrevive si se integra en sociedad, lo que significa crear vínculos, relaciones y actitudes cooperativas entre personas que se reconocen mutuamente. Es Hegel quien primeramente hace ver la necesidad del ser humano de constituir la relación consigo mismo, con el fin de desarrollar la «integridad personal» necesaria para convivir con los otros. Desde hace algunos años, revive su pensamiento con el desarrollo de una ética del reconocimiento ${ }^{25}$. «La conciencia de sí del ser humano depende de la experiencia de reconocimiento social $»^{26}$. El reconocimiento entre personas ocurre a tres niveles: en la naturaleza primaria de necesidades materiales y afectivas; en la constitución personal de una moralidad responsable; y en la conciencia de poseer ciertas competencias de funcionamiento cooperativo en la sociedad - reverbera aquí el concepto de empoderamiento de Sen-. En conjunto, estos modos de reconocimiento conforman la identidad de la persona en la autoconfianza, la autoestima y la valoración de sí. «Son moralmente vulnerables solo aquellos seres vivos que pueden relacionarse reflexivamente con sus propias vidas en el sentido de estar

21 MILLER, Franklin \& Howard BRODY. «A Critique of Clinical Equipoise. Therapeutic Misconception in the Ethics of Clinical Trials». The Hastings Center Report, 33, 3 (2003), pp. 19-28, p. 25.

22 JOFFE, Steven \& Franklin MilLer. «Bench to Bedside: Mapping the Moral Terrain of Clinical Research". The Hastings Center Report, 38, 2 (2008), p. 40.

23 PARK, Stephanie \& Mitchell GraYson. "Clinical Research: Protection of the "Vulnerable"?». The Journal of Allergy and Clinical Immunology, 121, 5 (2008), p. 1103.

24 HONNETH, Axel. «Recognition and Moral Obligation». Social Research, 64, 1 (1997), p. 28.

25 Honneth, Axel. Crítica del agravio moral. Buenos Aires: Fondo de Cultura Económica de Argentina, 2009.

26 HoNNETH, Axel. «Recognition and Moral Obligation», p. 20. 
volitivamente preocupadas de su propio bienestar ${ }^{27}$. Las incertidumbres y obstáculos para el cumplimiento de estas tres etapas de reconocimiento tienen marcada relevancia en la presente discusión por cuanto introducen el concepto de «vulnerabilidad moral», además de develar, por un lado, la importancia del reconocimiento riguroso, preciso y libre de la vulnerabilidad humana y, por el otro, de vulneraciones específicas que sufren individuos y sociedades.

\section{DERECHOS HUMANOS \\ III.1. Derecho natural}

Jacques Maritain pone al día la definición de Tomás de Aquino sobre derecho natural: «Es la participación en la Ley Eterna otorgada a la criatura racional lo que se denomina Ley Natural», y agrega otra cita aclaratoria: «Todo conocimiento de la verdad es una especie de reflejo de, y participación en, la Ley Eterna, que es la verdad inmutable [...] En realidad, si Dios no existe, la Ley Natural carece de poder impositivo. Si la Ley Natural no incluye la razón divina, no es ley, y si no es ley, no obliga». De este modo, Maritain contraviene la opinión de Grotius de que aun si Dios no existiese — pensamiento absurdola ley natural igualmente mantendría «su dominio y su autoridad sobre nosotros». Puesto que el derecho natural se basa en la naturaleza humana, regula deberes y derechos «que se conectan "necesariamente" con el primer principio: "Haz el bien y evita el mal"». La vinculación con derechos humanos está dada en el mismo texto: «La misma ley natural que fija nuestros deberes más fundamentales, en virtud de las cuales cada la ley es vinculante, es la ley que nos asigna nuestros derechos fundamentales» ${ }^{28}$.

La ley positiva, o cuerpo de leyes (consuetudinarias o estatutarias) vigentes en un determinado grupo social,

[...] se refiere a los derechos y deberes que se conectan con el primer principio, pero de un modo contingente, en virtud de determinadas formas de conducta establecidas por la razón y la voluntad humana cuando instituyen las leyes o dan nacimiento a costumbres en una sociedad particular, de este modo aseverando de sí mismas que en ese grupo en particular ciertas cosas serán buenas y permisibles, otras siendo malas y no permisibles ${ }^{29}$.

Maritain concede que hay «transiciones imperceptibles (al menos desde el punto de vista de la experiencia histórica) entre Ley Natural,

27 Ibídem, p. 23.

28 Maritain, Jacques. Natural Law. Reflections on Theory and Practice. South Bend: St. Augustine's Press, 2001, p. 58.

29 Ibídem, p. 64.

VULNERABILIDAD

ENTRE DERECHOS

HUMANOS

Y BIOÉTICA.

RELACIONES

TORMENTOSAS,

CONFLICTOS

INSOLUTOS

VULNERABILITY,

HUMAN RIGHTS,

AND BIOETHICS.

TURBULENT

RELATIONSHIPS,

UNSOLVED

CONFLICTS 
Ley de las Naciones, y Ley positiva ${ }^{30}$, lo cual abre las puertas para que la filosofía pragmática desarrolle una visión más sobria y critica de los derechos humanos.

De este complejísimo y multifacético temario político, jurídico y moral, el presente ensayo solo extrae algunos aspectos necesarios para proseguir su objetivo de analizar las relaciones entre derechos universales y bioética para enfrentar y proteger la vulnerabilidad humana. Es de notar que los derechos humanos universales son invocados menos como afirmación que como protesta y negación cuando son violados, al punto que algunas orientaciones políticas sostienen que «tal vez no podamos crear democracias o constituciones. La libertad liberal [en algunas sociedades] puede estar lejos de realizarse. Pero al menos podríamos hacer más de lo que hacemos para frenar sufrimientos inmerecidos y crueldades físicas ingentes ${ }^{31}$.

\section{III.2. Derechos ciudadanos}

Nadie podrá razonablemente negar la excelencia ética de los derechos humanos, aunque persisten más discusiones de lo deseable sobre la necesidad de excepcionalmente promover la violación de derechos esenciales $^{32}$. No obstante, la generalidad de estos derechos solo «implica un derecho universal a la política», debiendo reconocerse tanto como derechos políticos como también de participación política, ejercidos como ciudadano, es decir, en tanto miembro de una comunidad social y política ${ }^{33}$.

El nacimiento de cada ser humano lo sitúa como poseedor de derechos esenciales que, al unir natividad con nacionalidad, concede derechos ciudadanos a todos los que nacen en un territorio y luego ejercen sus derechos políticos en ese ámbito nacional. Este pensamiento esconde toxicidades tremendas, por cuanto si los derechos humanos arraigan en quienes nacen con el atributo único de ser humanos y deben transformarse en derechos ciudadanos, creando con ello bordes de exclusión. En el otro extremo, los derechos humanos en cuanto naturales son lo único que queda a los individuos que son degradados a la nuda existencia de homo sacer — Guantánamo, Abu Ghraib-

30 IgnatiefF, Michael, citado en Brown, Wendy. «"The Most We Can Hope For...". Human Rights and the Politics of Fatalism". Southern Atlantic Quarterly, 103, 2-3 (2004), p. 452.

31 Sobre todo a raíz de los ataques terroristas en recientes años, resurge entre algunos filósofos la justificación de las guerras santas y la tortura, siendo denunciados como la degradación de seres humanos a la categoría de homo sacer (AGAMBEN, Giorgio. Homo sacer. Valencia: Pre-Textos, 2003) o «musulmanes» (LeVI, Primo. Si esto es un hombre. Barcelona: Muchnik Editores, 2003). Cursa, asimismo, la afirmación de que el terrorista ha dejado de participar en los derechos humanos (Gross, Michael. Bioethics and Armed Conflict. Cambridge, Mass: The MIT Press, 2006).

32 BALIBAR, Étienne. «Is Philosophy of Human Civic Rights Possible? New Reflections on Equaliberty». South Atlantic Quarterly, 103, 2-3 (2004), p. 312.

33 RANCIĖRE, Jacques. «Who Is the Subject of the Rights of Man?». South Atlantic Quarterly, 103, 2-3 (2004), p. 302. 
o son marginados de ejercer derechos ciudadanos por no ser nacionales, sino inmigrantes marginados y excluidos. Estos desposeídos mantienen, por definición, los derechos humanos, pero no pueden hacer uso de ellos de modo que, al decir de Hannah Arendt, siendo derechos de quienes no tienen derechos, son la «mera burla de derechos». Desarrollando estos pensamientos y los de Giorgio Agamben, el filósofo francés Jacques Rancière llega a una fórmula paradójica: «los Derechos Humanos son los derechos de quienes no poseen los derechos que tienen y tienen los derechos que no poseen ${ }^{34}$. Lo importante es que los excluidos, que no pueden hacer uso de sus derechos ciudadanos, mantienen el derecho de luchar por la obtención de esos derechos en circunstancias en las que son impotentes para hacerlo. La inferencia política es que el ser humano prepolítico no tiene poder para hacer valer su derecho a poseer derechos, o sea, tiene el derecho, pero no puede ejercerlo. En consecuencia, se desencadenan movimientos humanitarios que asumen en forma vicariante un «derecho a interferencia humanitaria» en un movimiento que equivale a la devolución postal al remitente: quienes proclaman los atropellos a los derechos humanos reconocen la impotencia de las víctimas para protegerse y retoman la lucha por adjudicar estos derechos, lo cual ocurre bajo las consignas políticas del «liberador». En suma, las fuerzas neoliberales implantan su modalidad de democracia que presupone lo que Balibar llama ecualibertad, pero sometida a las inclemencias del mercado y de la globalización.

La comunidad humana reconoce la igualdad y libertad de todos, pero al transformarse en sociedad, inevitablemente crea divisiones de trabajo, jerarquías y áreas de poder que obstaculizan la igualdad y restringen la libertad individual ${ }^{35}$. Echando por tierra la proclamada universalidad de los derechos humanos, develan estos esclarecimientos inconsecuencias que requieren reflexión antes que aceptación incuestionada, así reconocer las brechas que aparecen al contrastar la Realpolitik con las declaraciones oficiales.

\section{III.3. Críticas culturales}

Los derechos humanos son un constructo de la cultura occidental, fuertemente arraigada en los valores del individuo. El pensamiento asiático no se siente interpretado por esos derechos desde una visión de mundo que da más importancia a las relaciones humanas — familia_ y a la integración de lo humano con la naturaleza. En otros 
modos de pensar, los derechos humanos son secundarios a lealtades trascendentes cuya defensa requiere amenazar y destruir vidas humanas.

Una crítica considerable proviene de quienes señalan que el respeto humano a los derechos cívicos y políticos promueve un statu quo que se sostiene paradójicamente en base a una violación estructural de derechos que no es reconocida por los perpetradores y, por lo tanto, se vuelve persistente. La pretendida universalización de los derechos humanos obtura la visión de diferencias étnicas o de género; del pensamiento feminista proviene el reclamo de que los derechos de la mujer le son propios qua mujer, buscando además la igualdad no discriminatoria y la afirmación de su especificidad ${ }^{36}$. Una similar bandera ha sido enarbolada por minorías étnicas que bregan por el derecho a la diferencia. Esta crítica es ampliada al reconocer que el sujeto de derechos universales es abstracto y que, al aplicarse al ciudadano inmerso en prácticas políticas y sociales, se introduce una «brecha entre la universalidad de los derechos humanos y los derechos políticos del ciudadano» ${ }^{37}$.

\section{BIOÉTICA Y DERECHOS HUMANOS}

Las reflexiones de Jonathan Mann son posiblemente las primeras en vincular derechos humanos con ética de la salud pública, una línea continuada especialmente en Latinoamérica por destacados autores empeñados en marcar la indisolubilidad y especificidad del vínculo entre bioética y derechos humanos. «La bioética de los Derechos Humanos no es más que la postulación de una moral universalmente reconocida ${ }^{38}$. Una vinculación transparente entiende a la bioética como encargada de «ocuparse de pensar la salud [...] como un derecho inalienable»" ${ }^{39}$. Por otra parte, los discursos bioéticos están en permanente riesgo de desgranarse bajo influencia de diversos contextos culturales, adoptando una postura de oposición a todo fundamentalismo o pretensión de universalidad que consecuentemente también debiera oponerse a la universalización de derechos.

Con la proclamación de la Declaración Universal de Bioética y Derechos Humanos (2005), se logró todo menos el anhelado consenso moral, más bien desencadenando una polémica sobre la oportunidad de una Declaración en circunstancias en las que la bioética está plagada de controversias y desacuerdos. La discusión provocó el mordaz comentario de que la bioética no es «una plaza de juegos para políticos y expertos

36 ŽıŽEK, Slavoj. «Against Human Rights». New Left Review, 34 (2005), p. 130.

37 TEALDI, Juan Carlos. «Bioética de los Derechos Humanos». En TEALDI, Juan Carlos (ed.). Diccionario latinoamericano de bioética. Bogotá: Unesco/Universidad Nacional de Bioética, 2008, p. 180.

38 PFEIFFER, María Luisa. «Ética y derechos humanos. Hacia una fundamentación de la bioética». Revista Brasileira de Bioética, 2 (2006), p. 297.

39 LANDMAN, Willem \& Udo SCHÜKLENK. "Unesco "Declares" Universals on Bioethics and Human Rights. Many Unexpected Universal Truths Unearthed by UN Body». Developing World Bioethics, 5, 3 (2005), p. vi. 
nombrados por los gobiernos para divagar en forma inconsecuente, discutible y no muy sofisticada sobre ética ${ }^{40}$. La calidad y coherencia de estas críticas no son relevantes en el presente contexto, ni tiene valor retórico reclamar que una declaración internacional es incapaz de influir sobre culturas y costumbres, una crítica que habrá de valer para toda propuesta ética. Lo que ha de quedar es que una documento tan controvertido como la Declaración difícilmente puede ser invocado como un sostén teórico y político robusto para impulsar el debate bioético.

Eslabonar bioética y derechos humanos es la mixtura inestable entre un discurso ético prioritariamente dirigido al individuo, y una proclamación política dirigida a los Estados. Es cierto que los derechos humanos se refieren a las personas y que el Estado es llamado a ser el garante de su cumplimiento, pero esta fórmula se complica al reconocer que la clasificación de derechos humanos de primera, segunda y tercera generación son del todo artificiales: «los derechos humanos están formulados para asegurar no solo la libertad de elegir entre opciones, sino también la libertad para establecer opciones de vida ${ }^{41}$. En consecuencia, la bioética no podría dejar de incursionar en el terreno de la política para impulsar las iniciativas estatales por empoderar a sus ciudadanos, mas tampoco podrá dejar de lidiar con quienes señalan que los derechos humanos solo podrán «ser efectivos y capaces de guiar la acción» si logran enfrentar problemas contextuales de escasez y prioridades: «En otras palabras, los derechos humanos institucionales no son, estrictamente hablando, derechos humanos inalterados. Más bien, presentan semejanzas con derechos políticos que son reconocidos por Estados en base a su propia política cultural y prioridad de valores ${ }^{42}$. La universalidad queda desmentida por la Realpolitik y por los avatares de la Lebenswelt, que determinan lo factible; queda mellada toda garantía de que los derechos primarios serán respetados, lo que en la vida real significa que el Estado se declara insolvente para asegurar tanto derechos negativos - falta de policías para proteger contra agresiones-, como positivos de atención médica, educación, etcétera: «La Declaración Universal adopta una visión simple e insatisfactoria sobre los deberes requeridos para asegurar derechos: los asigna a los Estados. Convenientemente ignora la realidad que algunos Estados no se comprometen con derechos y otros son demasiado débiles para asegurarlos» ${ }^{43}$. Queda en evidencia la incapacidad intrínseca de los derechos humanos para servir

40 TEALDI, Juan Carlos. «Bioética y Derechos Humanos». Revista Brasileira de Bioética, III (2007), p. 374.

41 ARRAS J.D. \& E.M. FEnTon. «Bioethics \& Human Rights: Access to Health-Related Goods». The Hastings Center Report, 39, 5 (2009), p. 35.

42 O'NeILL, Onora. A question of trust. Cambridge: Cambridge University Press, 2002, p. 30.

43 SInger, Peter. Practical Ethics. Cambridge: Cambridge University Press, 1979.

VULNERABILIDAD ENTRE DERECHOS

HUMANOS

Y BIOÉTICA.

RELACIONES

TORMENTOSAS,

CONFLICTOS

INSOLUTOS

VULNERABILITY,

HUMAN RIGHTS,

AND BIOETHICS.

TURBULENT

RELATIONSHIPS,

UNSOLVED

CONFLICTS 
de plataforma estable que estimule un lenguaje bioético generalizable al mismo tiempo que protector de los individuos.

Un escollo insalvable para la reflexión bioética es que no tiene claridad sobre lo que es un derecho e incurre en profundas discrepancias sobre lo que significa «humano». Un derecho es un privilegio voluntariamente reclamable, cuya legitimidad proviene de ser socialmente aceptado, y cuya validez depende de que alguien asuma la obligación correlativa de satisfacer ese derecho. En cuanto a lo humano, la dotación genética tradicionalmente considerada como definitoria de humanidad ha sido cuestionada por la manipulación de genes y por algunos pensadores que rechazan la prioridad ética de lo humano como un «especieismo» injustificado ${ }^{44}$.

El Pacto de San José de Costa Rica señala que «toda persona tiene derecho a que se respete su vida». Lo que parece un postulado universal no lo es desde el momento en que no tenemos una definición concordada de persona, ni siquiera hay acuerdo sobre si persona es sinónimo de ser humano, o si se refiere, como todas las definiciones indican - Boecio, Santo Tomás, Kant, Locke—, a seres humanos racionales. Carecemos, incluso, de consenso sobre cuándo comienza la vida humana, y sobre si una persona privada de actividad cerebral cortical —estado vegetativo persistente- mantiene los atributos de un ser humano, lo que parece puesto en duda por el término vegetativo.

El automatismo hermenéutico de presentar el concepto de persona como un hecho antropológico determinado e indiscutible, tendrá que lidiar con lo dicho por Simone Weil: «lo que es sagrado, muy lejos de ser la persona, es lo que en un ser humano resulta impersonal. Todo lo que es impersonal en el hombre resulta sagrado, y solo eso» ${ }^{45}$.

Labioética brega con estas polémicas y con las permisiones o prohibiciones que de ello derivan: ies el aborto una interrupción del embarazo o un homicidio? ise respetan los postulados de muerte digna cumpliendo con los deseos eutanásicos del paciente, o más bien instituyendo medidas paliativas y de soporte aun eventualmente contra la voluntad del enfermo y sus prójimos? Son problemas bioéticos crónicos en su persistencia, agudos en las angustias y sufrimientos que los acompañan, donde el recurso a los derechos humanos en nada ayuda porque no ofrece certeza de estar empleando conceptos básicos consensuados.

El respeto a la vida siempre alberga excepciones, como es el homicidio en defensa propia y el jus ad bellum, así como la pena de muerte 
o la condena a encarcelamiento de por vida, ambas violaciones del derecho a la vida porque cercenan y reducen la existencia humana. Justificado o no, el hecho es que la ley y la moral conocen el derecho a negar el derecho a la vida, de este modo niegan la universalidad, la naturalidad y la esencialidad de los derechos humanos. Imposible pasar por alto «la insuperable antinomia de aquello que se dio en llamar [derechos naturales], es decir, la aporía de definir como natural un artificio o como artificial un hecho de la naturaleza», acentuando de este modo el naufragio conceptual de la bioética ${ }^{46}$.

\section{BIOÉTICA Y VULNERABILIDAD}

La vulnerabilidad es un tema sobreexpuesto en la literatura bioética que ha dado lugar a una diversidad extrema de interpretaciones y definiciones, creando un abanico conceptual que va desde considerar la vulnerabilidad como el «principio ontológicamente prioritario ante otros principios» ${ }^{47}$, hasta preguntar si acaso es «un principio fútil o útil en la ética de la asistencia sanitaria» ${ }^{48}$. $\mathrm{Al}$ interior de esta diversidad se detecta una fuerte tendencia a utilizar el concepto con fines pragmáticos, amalgamando la fragilidad con el daño instalado y con deficiencias de autonomía. Es necesario, por ende, reconstruir un concepto contemporáneo que incorpore dos premisas ineludibles: 1) la secularización del pensamiento occidental obliga a entender la vulnerabilidad independientemente de creencias religiosas que podrán ser válidas al interior de ciertas doctrinas, pero no son generalizables; 2) la vulnerabilidad como característica existencial de un ser arrojado en el mundo queda trunca, pues más que arrojado, el ser humano es primariamente relacional, se encuentra desde siempre instalado en, y relacionado con, el mundo, lo cual significa que todo proyecto existencial se realiza a través de interconexiones con otros seres humanos ${ }^{49}$.

A este fundamento relacional apunta la ética del reconocimiento al situar la vulnerabilidad moral en la base de la existencia humana, con sus tres momentos: supervivencia biológica, empoderamiento social y competencia moral. Reconocidos estos tres niveles, el ser humano se sabe miembro de una especie existencialmente vulnerable, es decir,

46 Koтtow, Miguel. Bioética relacional. Saarbrücken: Editorial Académica Española, 2012 (en prensa). 47 «icuán pomposa e inútilmente son [los derechos] llamados <humanos>!» acusa Esposito, para luego añadir: «el simple repaso estadístico, en términos absolutos y relativos, de los muertos por el hambre, por las enfermedades, por la guerra, que marcan todos los días del calendario contemporáneo, parece refutar de por sí la propia enunciación de un derecho a la vida» (ESPOSITO, Roberto. Ob. cit., p. 44 ).

48 MORALES GIL DE LA TORRE, Héctor. «Introducción: notas sobre la transición en México y los derechos humanos». En MORALES GIL DE LA TORRE, Héctor (coord.). Derechos humanos: dignidad y conflicto. México D.F.: Universidad Interamericana, 1996, p. 19.

49 O'NeILL, Onora. Towards Justice and Virtue. A Constructive Account of Practical Reasonin. Cambridge/Nueva York: Cambridge University Press, 1998.

VULNERABILIDAD ENTRE DERECHOS

HUMANOS

Y BIOÉTICA.

RELACIONES

TORMENTOSAS,

CONFLICTOS

INSOLUTOS

VULNERABILITY,

HUMAN RIGHTS,

AND BIOETHICS.

TURBULENT

RELATIONSHIPS,

UNSOLVED

CONFLICTS 
acechado por los peligros y riesgos de sucumbir y la necesidad de lograr protección cooperativa contra estas amenazas.

La pregunta que surge es si acaso el reconocimiento de la vulnerabilidad moral y existencial solicita en forma perentoria una respuesta protectora y, de ser así, a quién apela este requerimiento de resguardo. La ética del reconocimiento habla por de pronto de la relación que los seres humanos establecen entre sí, relaciones naturales y sociales que son necesarias, fructíferas y asumidas con la responsabilidad mutua derivada de la ética de esas relaciones, pero deja sin comentar el vector político que las regula.

La vulnerabilidad existencial significa que todo ser humano desarrolla su proyecto de vida en cooperación con los demás, lo cual presupone que todos los miembros de la especie humana son moralmente iguales entre sí, y libres de desarrollar su existencia en tanto no coarten otras libertades. Todo ser humano es libre para operar conjuntamente en el fomento y la mantención de esa igualdad y esa libertad, como lo proclama la Declaración Universal de Derechos Humanos en sus primeros tres artículos, el resto siendo especificaciones de las premisas básicas. Al no ir más allá de ratificar la libertad y la igualdad, los derechos fundamentales requieren ser complementados mediante agregados que hablen de los derechos de segunda, tercera y cuarta generación. Dado su origen iuspositivista, no pueden estos derechos políticos y sociales pretender universalidad y, por ende, crean crecientes brechas entre proclamación y realización.

La universalidad de los derechos humanos, consistente en el llamado a la igualdad y libertad, los hace totalmente coincidentes con la definición amplia de lo que es la ética: una reflexión sobre actos humanos realizados en libertad y con responsabilidad entre iguale ${ }^{50}$. Los derechos humanos, al igual que la ética, reconocen los elementos fundacionales de la vida humana relacional, que se han definido como «las condiciones que permiten crear una relación integrada entre la persona y la sociedad ${ }^{51}$. Los derechos humanos universales apelan a la necesidad de fomentar condiciones que permitan proteger la vulnerabilidad existencial de todo ser humano. Notorio es lo abstracto de su definición, que no contempla la necesidad de intercesión y reparación cuando estas condiciones no se dan por cuanto la relación interpersonal y con la sociedad queda trunca. Toda existencia humana sufre vulneraciones —enfermedades, pérdidas, rupturas - y una substancial mayoría de la humanidad lleva 
una existencia irremediablemente vulnerada por miseria, desnutrición, mortalidad prematura, dejando en evidencia que la proclamación de los derechos humanos universales no es capaz de proteger la vulnerabilidad intrínseca de la vida humana.

\section{BIOÉTICA COMO ÉTICA APLICADA}

Útil resulta recordar la distinción de Max Weber entre razón teleológica - Zweckrationalität - y razón valórica - Wertrationalität—, sobre todo en su reformulación por Habermas, quien habla de razón instrumental empeñada en mejorar la adaptación del ser humano, y de razón comunicativa cuyo norte es su emancipación, vale decir, la reducción de dependencias coercitivas y arbitrarias. La razón instrumental fagocita a la razón comunicativa, ejerciendo una cada vez mayor hegemonía de metas pragmáticas, instalando determinantes tecnocientíficas insensibles a toda ponderación ética.

Surge la necesidad de generar instrumentos jurídicos y políticos para enfrentar las vulneraciones que los seres humanos inevitablemente sufren en el transcurso de sus vidas, requiriendo instancias sociales de reparación (O’Neill) y empoderamiento (Sen) para fortalecer la capacidad propia de defensa contra daños y la adquisición de instrumentos de realización.

Los derechos humanos de segunda generación hacen hincapié en bienes y servicios que todo ser humano requiere para sobrevivir y desarrollar su proyecto de vida, conociéndose esta aspiración bajo el nombre algo ambiguo de derecho a bienestar, para diferenciarla de los derechos a libertad consagrados en la Declaración Universal de los Derechos Humanos de primera generación. Los derechos a bienestar requieren para su cumplimiento de la institucionalización social de la razón instrumental. Es aquí donde se produce un hiato entre proclamación de derechos y asunción de obligaciones, dado que las declaraciones pretenden validez universal de derechos, mas se estrellan con cumplimientos limitados por factores coyunturales ${ }^{52}$.

Las instituciones sociales que proporcionan los bienes y servicios en reconocimiento de los derechos de bienestar difícilmente cumplirán su cometido si se disponen a esperar la presentación de los requirentes de derechos en vez de asumir las obligaciones de atención ante todos los necesitados, tengan o no estos la competencia para exigir sus derechos. Solo asumiendo proactivamente sus obligaciones podrán

VULNERABILIDAD ENTRE DERECHOS HUMANOS

Y BIOÉTICA. RELACIONES TORMENTOSAS, CONFLICTOS INSOLUTOS

VULNERABILITY, HUMAN RIGHTS, AND BIOETHICS. TURBULENT RELATIONSHIPS, UNSOLVED CONFLICTS 
las instituciones sociales alcanzar a los marginados y desempoderados demasiado débiles para demandar sus derechos.

De allí que el lenguaje de obligaciones sea más vinculante en su compromiso y más controlable en su cumplimiento que la proclamación de derechos. Las obligaciones de proveer servicios y bienes básicos son universales por corresponderle a todo ser humano, son especiales al originarse «en roles, instituciones y relaciones específicas», y son obligaciones perfectas desde el momento que son identificables los portadores de deberes y los portadores de derechos. Las «obligaciones especiales y perfectas requieren estructuras sociales o prácticas que conectan a agentes específicos con receptores de acción a su vez específicos, a quienes aquellos se deben y para quienes tienen el deber de proveer, siendo que estos son los detentores de los respectivos derechos especiales $»^{53}$.

Para la bioética, detentores de derechos son todos quienes sufren afectación de su vulnerabilidad por daños a su integridad corpórea, especialmente si su desmedro les impide acceder a las instituciones de atención médica e integrarse activamente a la prevención de enfermedades, o si viven en condiciones de carencia de recursos en un medio dañado o deficitario ${ }^{54}$. Es tarea de la bioética velar porque los servicios y bienes proporcionados a los vulnerados cumplan con los requerimientos de la razón comunicativa y sean conducentes a la emancipación de personas y comunidades, velando por lograr el empoderamiento de los vulnerados para obtener o recuperar sus capacidades básicas, incluyendo participación social y política ${ }^{55}$. La sociedad debe empoderar a las personas a fin de permitir su participación en la formación y formulación de políticas públicas de corrección de vulneraciones; compensaciones de desigualdades injustas; y la forja de un espacio privado de ejercicio autónomo de capacidades e inmune a intervención pública indebida.

Parafraseando la Undécima tesis de Marx sobre Feuerbach, puede decirse que la bioética ha seguido el camino fácil de abrir las puertas de los derechos, ahora le corresponde golpear las aldabas de las obligaciones.

\footnotetext{
53 lbídem, p. 147.

54 «Una sobredependencia de lo que las personas "logran desear" es una de los aspectos limitantes de la ética utilitarista, que es notoriamente indiferente a los reclamos de quienes viven demasiado subyugados o quebrados para tener el coraje de desear mucho" (SEN, Amartya. Inequality Reexamined. Cambridge, Mass.: Harvard University Press, 1995, p. 149).

55 Sen, Amartya. Development as Freedom. Nueva York: Alfred A. Knopf, 2000.
} 
La reflexión ética que termina en una conclusión ${ }^{56}$, como suele ser requerida en el mundo editorial, es una contradicción en sí. Solamente una ética dogmática y soberbia en su pretensión de verdad puede ufanarse de haber llegado a puerto. Lo cual es una falacia, por cuanto la ética es fundamentalmente propositiva y, por ende, su misión es abrir abanicos y no cerrar puertas.

Muy brevemente, se trata de recordar la profunda antinomia entre biopolítica y bioética, la primera ejerciendo poder sobre la vida humana nuda, desprovista de su personalidad, el homo sacer de Agamben. En contraste, la bioética se centra en la persona olvidando, en ocasiones, que existen vidas humanas carentes de los atributos de persona y que son, qué duda cabe, miembros de la comunidad moral, sujetos morales aun cuando no puedan ser agentes morales.

Pues bien, la biopolítica, que es descrita como el poder que autoriza la muerte para proteger la vida, requiere de un vuelco que la transforme en una biopolítica afirmativa, «ya no definida por el poder sobre la vida, como el que conoció el siglo pasado en todas sus tonalidades, sino por el poder de la vida ${ }^{57}$. «No es admisible que el derecho [...] imponga desde afuera y desde arriba sus propias leyes a una vida separada de sí misma: es la vida, en su composición al mismo tiempo corpórea e inmaterial, la que debe hacer de sus propias normas la referencia constante de un derecho cada vez más ajustado a las necesidades de todos y cada uno» ${ }^{58}$.

Quede esbozado para futura reflexión, que la biopolítica afirmativa propuesta por Esposito es en realidad un proyecto bioético tanto por el lenguaje que emplea, como por el hecho que la biopolítica, al abandonar el empleo del poder, deja de ser una biopolítica. Esposito insiste en la idea de una biopolítica afirmativa en parte porque erróneamente cree que los «máximos exponentes de la bioética», «liberal según su propia definición» son «Peter Singer y Hugo Engelhardt», para quienes los seres humanos con personalidad defectuosa «están expuestos al derecho de vida y muerte por parte de aquellos que las custodian $»^{59}$.

La bioética racional y laica comparte la idea de que las normativas de la vida han de provenir de ella y no desde afuera y desde arriba, tarea que la bioética hace suya mediante reflexión y deliberación. Se completa de este modo el trayecto trazado desde una bioética que reconoce como trascendental la igualdad y libertad de todo ser humano, así como su vulnerabilidad moral y existencial. Mas esta

56 «Concluir (Del lat. concludēre; de cum, con, y claudēre), cerrar» (Diccionario de la lengua española). 57 lbídem, p. 32.

58 Pellegrino, Edmund \& David Thomasma. A Philosophical Basis of Medical Practice. Nueva York/ Oxford: Oxford Univeristy Press, 1981, p. 73.

59 Ibídem, p. 32.

VULNERABILIDAD

ENTRE DERECHOS

HUMANOS

Y BIOÉTICA.

RELACIONES

TORMENTOSAS,

CONFLICTOS

INSOLUTOS

VULNERABILITY,

HUMAN RIGHTS,

AND BIOETHICS.

TURBULENT

RELATIONSHIPS,

UNSOLVED

CONFLICTS 
tarea de reconocimiento es la antesala para ocupar un escenario donde diseñar las responsabilidades y obligaciones de proteger y empoderar a los vulnerados «en su composición corpórea e inmaterial». La bioética ha de superar la etapa de proclamación de derechos y enfatizar su rol prescriptivo de obligaciones para cuidar a quienes sus desmedros impiden cuidarse por sí mismos. Si la medicina fue definida como «la artesanía que involucra al cuerpo en la curación del cuerpo» ${ }^{60}$, sea la bioética entendida como «la ética que empodera al cuerpo a través del cuerpo». 